\title{
ANÁLISE DE CRESCIMENTO EM CLONES DE EUCALIPTO SUBMETIDOS A ESTRESSE HÍDRICO
}

\author{
Maria Renata Rocha Pereira ${ }^{1}$; Guilherme Sasso Ferreira de Souza ${ }^{2}$; Andreia Cristina \\ Peres Rodrigues $^{2}$; André Luiz Melhorança Filho ${ }^{3}$; Antônio Evaldo Klar ${ }^{1}$ \\ ${ }^{I}$ Departamento de Engenharia Rural, Faculdade de Ciências Agronômicas, Universidade Estadual Paulista, \\ Botucatu, SP, mariarenata10@hotmail.com \\ ${ }^{2}$ Departamento de Agricultura, Faculdade de Ciências Agronômicas, Universidade Estadual Paulista, Botucatu, \\ $S P$ \\ ${ }^{3}$ Universidade Federal de Acre, campus de Cruzeiro do Sul.
}

\section{RESUMO}

O estudo objetivou avaliar o desempenho de genótipos de plantas de Eucalyptus urograndis (clone 105 e 433) em relação à tolerância à seca, considerando a análise de crescimento das plantas. Para tanto, plantas foram cultivadas em vasos de 8 litros em casa de vegetação. $\mathrm{O}$ delineamento foi em inteiramente casualizado, com quatro tratamentos contendo desesseis repetições. O manejo hídrico foi estabelecido com base em dois potenciais mínimos de água $(\Psi):-0,03 \mathrm{e}-1,5 \mathrm{MPa}$, através da pesagem diária dos vasos. O desenvolvimento das plantas foi avaliado em coletas a intervalos de 15 dias, iniciando no momento de plantio da muda no vaso até os 60 dias após plantio. Considerando-se o acúmulo de matéria seca total (MS) e o índice de área foliar da planta (IAF) como base para a determinação dos seguintes índices fisiológicos: razão de área foliar (RAF), taxa assimilatória líquida (TAL), área foliar específica (AFE), taxa de crescimento relativo (TCR) e taxa de crescimento absoluto (TCA). Nas condições do experimento, o clone 105 apresentou menor sensibilidade ao déficit hídrico, o que o qualifica como material genético promissor para ambientes sujeitos a estiagem prolongada. Já em condições em que não há restrição hídrica, os dois clones tiveram comportamento semelhantes.

UNITERMOS: Eucaliptus urograndis, índices fisiológicos, potenciais hídricos do solo

\section{PEREIRA, M. R. R.; SOUZA, G. S. F. de; RODRIGUES, A. C. P.; MELHORANÇA FILHO, A. L.; KLAR, A. E. GROWTH ANALYSIS OF CLONE EUCALIPTUS UNDER HYDRIC STRESS}

\section{ABSTRACT}

The aim of this study was to evaluate Eucaliptus grandis genotypes (Clones 105 and 433) in relation to drought tolerance, through growth plant analysis. Black PVC pots with 10 liter volume were used for cultivate plants in polyethilene greenhouse oriented east/west. Completely randonmized design with four treatments was used: two clones and two minimum soil water potentials ( -0.03 and $-1,5 \mathrm{MPa}$ ) and sixteen replicates. Pots were weighed daily in order to evaluate water content and characteristic soli water curve was determined. Plant development was obtained each 15 days from planting until 60 days through total dry matter (DM), leaf area index (LAI), leaf area ratio (LAR), net assimilative ratio (NAR), specific leaf 
area (SLA), relative growth ratio (RGR) and absolute growth ratio (AGR). Results showed that clone 105 presented less sensibility to water deficit, which qualify it as genetic material for use under dry soil conditons. On the other hand, both clones had similar behavior with no water restrictions.

KEYWORDS: Eucaliptus grandis, soil water potentials, morphologic measurements.

\section{INTRODUÇÃO}

O conhecimento sobre a hidrologia e meteorologia de florestas plantadas vem atraindo atenção considerável de diversos pesquisadores nas ultimas décadas. Essa atenção deve-se à preocupação crescente das questões ambientais ligadas à produção florestal;

O crescimento e o desenvolvimento dos vegetais é conseqüência de vários processos fisiológicos e são controlados pelas condições ambientais e características genéticas de cada espécie vegetal. Portanto, para melhor compreender o crescimento, o desenvolvimento e a hidrologia de uma plantação de eucalipto, faz-se necessário conhecer os fatores que controlam o uso da água. (Tonello e Texeira Filho, 2007)

A ecofisiologia vegetal é a ciência que trata dos processos e das respostas vitais das plantas em função das mudanças nos fatores ambientais (Larcher, 2000).

De acordo com Gomes e Varriale (2001), para melhor entender os modelos hidrológicos, é necessário analisar os componentes envolvidos no ciclo hidrológico. A água é essencial no processo produtivo. A folha de uma planta é o principal órgão responsável pela fotossíntese e também o responsável pelo controle sobre o ciclo hidrológico através dos estômatos.

As variáveis biofísicas são importantes descritoras de florestas nativas ou implantadas. Por exemplo, a altura e o diâmetro à altura do peito das árvores (DAP) são freqüentemente utilizados em equações alométricas para o cálculo de volume de madeira. Outra variável biofísica importante é o índice de área foliar (IAF), definido por Watson (1947) como a área foliar integrada do dossel por unidade de superfície projetada no solo $\left(\mathrm{m}^{2} / \mathrm{m}^{2}\right)$.

O IAF está diretamente relacionado com a produtividade e a evapotranspiração de ecossistemas florestais (Lang \& Mcmurtrie, 1992). Para Soares et al. (1997) e Soares \& Almeida (2001), a evapotranspiração do dossel, quando integrada em um dado período de tempo, pode ser utilizada para expressar o potencial de produtividade da cultura em determinado local e período.

Do ponto de vista de plantações de eucalipto, por exemplo, é importante quantificar o IAF, assim como a sua variação ao longo de seu ciclo produtivo, pois a partir desta quantificação torna-se possível sua utilização como variável de entrada em modelos hidrológicos e de crescimento.

Computar o uso de água de plantações de eucalipto é fundamental tanto na avaliação de seus impactos ambientais quanto na aferição de sua sustentabilidade.

Os modelos de crescimento permitem, por outro lado, simular o efeito de variações climáticas e da fertilidade do solo sobre o potencial produtivo dessas plantações.

A análise de crescimento produz conhecimentos de valor prático e informações exatas, referentes ao crescimento e comportamento dos genótipos, que podem ser utilizadas pelos produtores permitindo escolher a cultivar que melhor se adapte a cada região (SHARMA et al., 1993). É um método que segue a dinâmica da produção fotossintética, sendo de vital importância para compreender os processos morfo-fisiológicos da planta e sua influência 
sobre o rendimento. Pode, ainda, ser empregada para determinar a produção líquida das plantas, derivadas do processo fotossintético, como resultado do desempenho do sistema assimilatório durante determinado período de tempo (Cardoso et al., 1987); permitindo também analisar os processos fisiológicos de crescimento e desenvolvimento das plantas.

A área foliar é um índice importante em estudos de nutrição e crescimento vegetal, uma vez que determina o acúmulo de matéria seca, o metabolismo vegetal, a capacidade fotossintética potencial, o rendimento e qualidade da colheita (Ibarra,1985; Jorge e Gonzalez, 1997).

Tendo em vista a escassez de resultados referentes ao desenvolvimento, tolerância e/ou sensibilidade à seca, de genótipos comerciais de Eucalyptus urograndis W. Hill ex Maiden. objetivou-se, nesta pesquisa, determinar e avaliar os índices fisiológicos da análise de crescimento com diferentes potenciais de água no solo.

\section{MATERIAIS E MÉTODO}

O experimento foi desenvolvido na Fazenda Experimental Lageado, Faculdade de Ciências Agronômicas, campus de Botucatu, UNESP, no período de março a julho de 2005, utilizando-se dois clones de Eucalyptus urograndis (433 e 105), cedidos pela Empresa Eucatex Florestal.

A casa de vegetação utilizada neste estudo é orientada no sentido leste/oeste.

O solo utilizado apresentou características constantes nas Tabelas 1 e 2.

Tabela 1. Granulometria e classificação textural do solo.

\begin{tabular}{|c|c|c|c|}
\hline Areia & Silte & Argila & \\
\hline 23,9 & 25,7 & 50,4 & Argilosa \\
\hline
\end{tabular}

Tabela 2. Análise química de fertilidade do solo.

\begin{tabular}{|c|c|c|c|c|c|c|c|c|c|}
\hline \multirow{2}{*}{$\begin{array}{c}\mathrm{pH} \\
\mathrm{CaCl}_{2}\end{array}$} & \multirow{2}{*}{$\begin{array}{c}\text { M.O } \\
\text { g/dm }\end{array}$} & \multirow{2}{*}{$\begin{array}{l}P \text { resina } \\
\mathrm{mg} / \mathrm{dm}^{3}\end{array}$} & \multicolumn{6}{|c|}{$\mathrm{mmol} / \mathrm{dm}^{3}$} & \multirow{2}{*}{$\begin{array}{c}V \\
(\%)\end{array}$} \\
\hline & & & $\begin{array}{l}\text { H+ } \\
\text { Al }\end{array}$ & $\mathbf{K}$ & $\mathbf{C a}$ & Mg & SB & $\begin{array}{c}\text { CT } \\
\text { C }\end{array}$ & \\
\hline 5,2 & 24 & 24 & 34 & 5,3 & 28 & 19 & 53 & 87 & 61 \\
\hline
\end{tabular}

Com base nesta análise química e de acordo com as necessidades da cultura, não foi necessária a adubação deste solo para o plantio de eucalipto. As mudas foram conduzidas pela empresa até o momento de ir a campo (90 dias), não havendo rustificação das mesmas. As relações entre os potenciais e os teores de água do solo foram determinadas pelo método da Placa de Pressão de Richards (Klar, 1984) e encontram-se na Tabela 3.

Tabela 3. Relações entre teores e potenciais de água do solo

\begin{tabular}{cccccccc}
\hline & \multicolumn{7}{c}{ Potencial (MPa) } \\
\cline { 2 - 8 } & Saturado & $\mathbf{- 0 , 0 1}$ & $\mathbf{- 0 , 0 3}$ & $\mathbf{- 0 , 0 5}$ & $\mathbf{- 0 , 1}$ & $\mathbf{- 0 , 5}$ & $\mathbf{- 1 , 5}$ \\
\hline $\begin{array}{c}\text { Umidade Base } \\
\text { Massa Seca (\%) }\end{array}$ & 52 & 26 & 24 & 22 & 21 & 21 & 19 \\
\hline
\end{tabular}


Foram utilizados vasos de polietileno preto com $8 \mathrm{Kg}$ do solo seco ao ar, já peneirado em malha de $5 \mathrm{~mm}$. A partir dos resultados da curva de potencial de água no solo, foram estabelecidos dois níveis potenciais mínimos de água do solo , -0,03 e -1,5 MPa (Tabela 4), fazendo-se a reposição da água com base na pesagem dos vasos (Tabela 4).

Tabela 4. Caracterização dos tratamentos de potencial mínimos de água no solo em clones de E. urograndis. Botucatu/SP, 2009.

\begin{tabular}{cccc}
\hline Tratamento & Clone & $\begin{array}{c}\text { Potencial de água no } \\
\text { solo (MPa) }\end{array}$ & $\begin{array}{c}\text { Umidade do } \\
\text { solo (\%) }\end{array}$ \\
\hline \hline T1 & 105 & $-0,03$ & $24 \%$ \\
T2 & 105 & $-1,5$ & $19 \%$ \\
T3 & 433 & $-1,5$ & $24 \%$ \\
T4 & 433 & $-0,03$ & $19 \%$ \\
\hline
\end{tabular}

Durante dois meses a partir da instalação do experimento, realizaram-se coletas quinzenais, onde retirava-se de cada tratamento uma amostra, ou seja, quatro plantas, perfazendo um total de quatorze plantas. Após eram determinadas a área foliar (AF) (calculada pelo método indireto massa da matéria fresca relacionada com a área conhecida); matéria seca total da folha, caule e raiz (MS). A matéria seca foi determinada por meio de secagem do material em estufa a $60^{\circ} \mathrm{C}$, até atingir massa constante.

Com a obtenção da AF e da MS, em intervalos regulares de tempo (T), determinou-se os índices fisiológicos descritos a seguir, com suas respectivas fórmulas matemáticas, de acordo com estudos dedicados à análise quantitativa do crescimento (Pereira \& Machado, 1987; Peixoto, 1998; Brandelero et al., 2002; Benincasa, 2004):

1 - Taxa de crescimento absoluto (TCA):

$\mathrm{TCA}=\mathrm{MS}_{2}-. \mathrm{MS}_{1} / \mathrm{T}_{2}-\mathrm{T}_{1}$

2 - Taxa de crescimento relativo (TCR):

$\mathrm{TCR}=\mathrm{Ln} \cdot \mathrm{MS}_{2} \mathrm{Ln} \cdot \mathrm{MS}_{1} / \mathrm{T}_{2}-\mathrm{T}_{1}$

Que expressam o incremento na massa de matéria seca (MS), por unidade de massa inicial, em um intervalo de tempo $\left(\mathrm{g} \mathrm{g}^{-1} \mathrm{dia}^{-1}\right)$, onde Ln é o logaritmo neperiano e T o tempo

3 - Razão de área foliar (RAF), que representa a relação entre a área foliar e a massa seca $\left(\mathrm{dm}^{2} \mathrm{~g}^{-1}\right)$ da planta:

$\mathrm{RAF}=\mathrm{AF} / \mathrm{MS}$

4 - Taxa assimilatória líquida (TAL), que representa a taxa de incremento de matéria seca (MS) por unidade de área foliar existente na planta, por unidade de tempo $\left(\mathrm{g} \mathrm{dm}^{-2} \mathrm{dia}^{-1}\right)$, obtida pela equação:

$\mathrm{TAL}=\left(\mathrm{MS}_{2}-\mathrm{MS}_{1}\right) \times\left(\mathrm{LnAF}_{2}-\mathrm{LnAF}_{1}\right) /\left(\mathrm{AF}_{2}-\mathrm{AF}_{1}\right) \times\left(\mathrm{T}_{2}-\mathrm{T}_{1}\right)$

5 - Área foliar específica (AFE), este parâmetro é calculado através da razão entre a área foliar e a massa seca das folhas:

$\mathrm{AFE}=\mathrm{AF} / \mathrm{MS}_{\text {folhas }}$

O delineamento experimental foi inteiramente casualizado, com esquema fatorial (dois níveis de água $\mathrm{x}$ dois materiais genéticos), com 16 repetições, perfazendo num total de 64 mudas. Para a análise estatística, foi utilizada análise de variância, seguido do teste de Tukey com nível de significância de $5 \%$, para a comparação de médias entre tratamentos e das interações dos desdobramentos ocorridos com o programa SISVAR. 


\section{RESULTADOS E DISCUSSÃO}

As equações exponenciais quadráticas ajustadas aos dados originais do índice de área foliar (IAF), com seus respectivos coeficientes de determinação, bem como as curvas e os valores médios observados, podem ser vistos na Figura 1. Constata-se que na primeira coleta não há distinção entre os tratamentos, uma vez que os manejos hídricos iniciaram no plantio, e a muda de eucalipto estava em fase de pegamento.

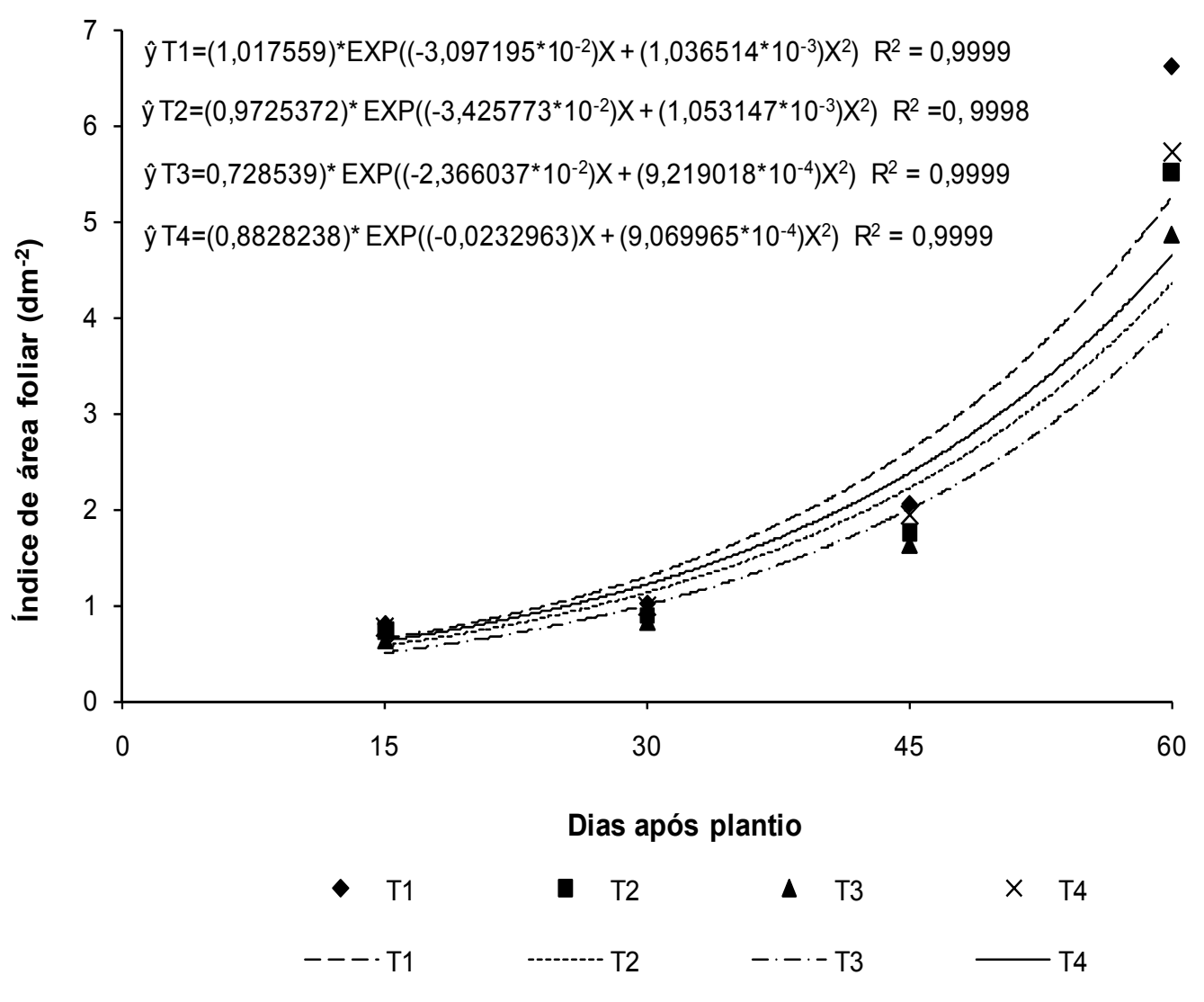

Figura 1. Índice de área foliar de dois genótipos de Eucalyptus urograndis submetidos a diferentes potenciais de água no solo. Botucatu, 2009.

A partir da segunda coleta, verifica-se pequena diferenciação entre os tratamentos, que progride significativamente ao longo do tempo. Os dois materiais genéticos tem um maior IAF, quando mantidos sem estresse hídrico, sendo maior para o clone 105, com diferença de 13,7\%. Em condições de restrição hídrica o clone 433 mostrou-se mais sensível, com as menores taxas de L, e redução de $11,8 \%$ em comparação ao clone 105 , com mesmo regime hídrico.

Comparando-se o mesmo clone, em diferentes condições hídricas no solo, o clone 433 teve seu IAF reduzida em 14,8\%, e o clone 105, 16,7\%, quando sob estresse hídrico, ao final dos sessenta dias de avaliação.

Considerando o IAF como um índice da eficiência funcional das partes produtivas de um vegetal (Hunt, 1982), pode-se inferir que o estresse hídrico afetou significativamente essa eficiência na cultura. A área foliar é um índice importante em estudos de nutrição e crescimento vegetal, uma vez que determina a acumulação de matéria seca, o metabolismo 
vegetal, a capacidade fotossintética potencial, o rendimento e qualidade da colheita (Ibarra,1985; Jorge e Gonzalez, 1997).

Resultados semelhantes foram encontrado por NeSmith e Ritchie (1992), em estudo com milho, observaram que houve decréscimos na área foliar de plantas de milho, quando estas foram submetidas à deficiência hídrica. Já Guimarães (1994), avaliando mudas de café sob influencia de auto-sombreamento e temperatura média, não verificou diferença no $L$ entre os tratamentos nos oito estádios de desenvolvimento estudados.

As médias de matéria seca total (MST), expressas pelo somatório da parte aérea da planta e das raízes, estão representadas na Figura 2. Pode-se observar que ao contrário do IAF, a MST foi maior no clone 433, sem restrição hídrica, este fato pode ser explicado devido á maior sensibilidade deste à seca, e mesmo quando há disponibilidade de água, este clone acumula mais matéria, ou seja, folhas, caule e raízes mais espessos com menor área.

Para os tratamentos submetidos a potencial de água no solo mais baixo, o comportamento foi o mesmo do IAF, sendo maior para o clone 105, comprovando a possível resistência deste à falta d'água, fato comprovado por Pereira et al. (2006), que trabalhando com os mesmos clones observou que o clone 105 foi o mais resistente ao estresse hídrico, não comprometendo seu desenvolvimento e produtividade, com maior eficiência no uso de água.

Os maiores acúmulos de MST foram atingidos entre os 45 e 60 dias após plantio para todos os tratamentos, sendo 3,5 g e 2,49 g, respectivamente para os clones 433 e 105, sem restrição hídrica. Com base nos resultados de IAF e MST, pode-se inferir que a partir dos 30 DAP, as mudas de eucalipto começam a acumular massa, emitir novas folhas, e que já estão adaptadas às condições de campo.

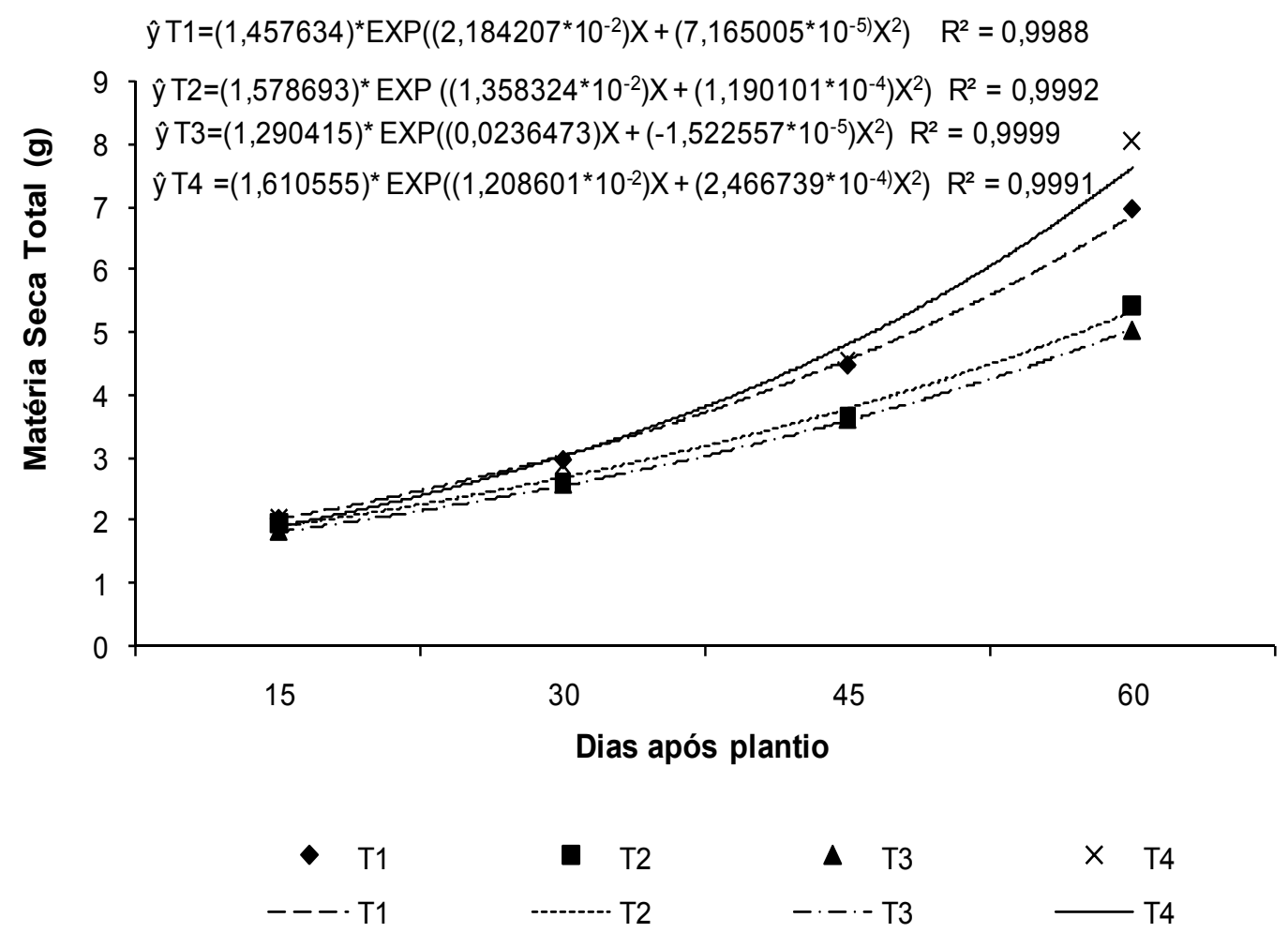

Figura 2. Matéria seca total de dois genótipos de Eucalyptus urograndis submetidos a diferentes potenciais de água no solo. Botucatu, 2009. 
Os índices de taxa de crescimento absoluto (TCA) corroboram os valores da matéria seca total, comprovando maior crescimento para o clone 433 não submetido à restrição hídrica durante todo o período desenvolvimento estudado, enquanto nos demais tratamentos submetidos à estresse hídrico, os resultados foram semelhantes (Figura 3). A TCA pode ser usada para se ter idéia da velocidade média de crescimento ao longo do período de observação (Benincasa, 2003). Assim, os tratamentos com potenciais de água no solo de $-0,03 \mathrm{MPa}$ proporcionaram maior velocidade de crescimento das plantas.
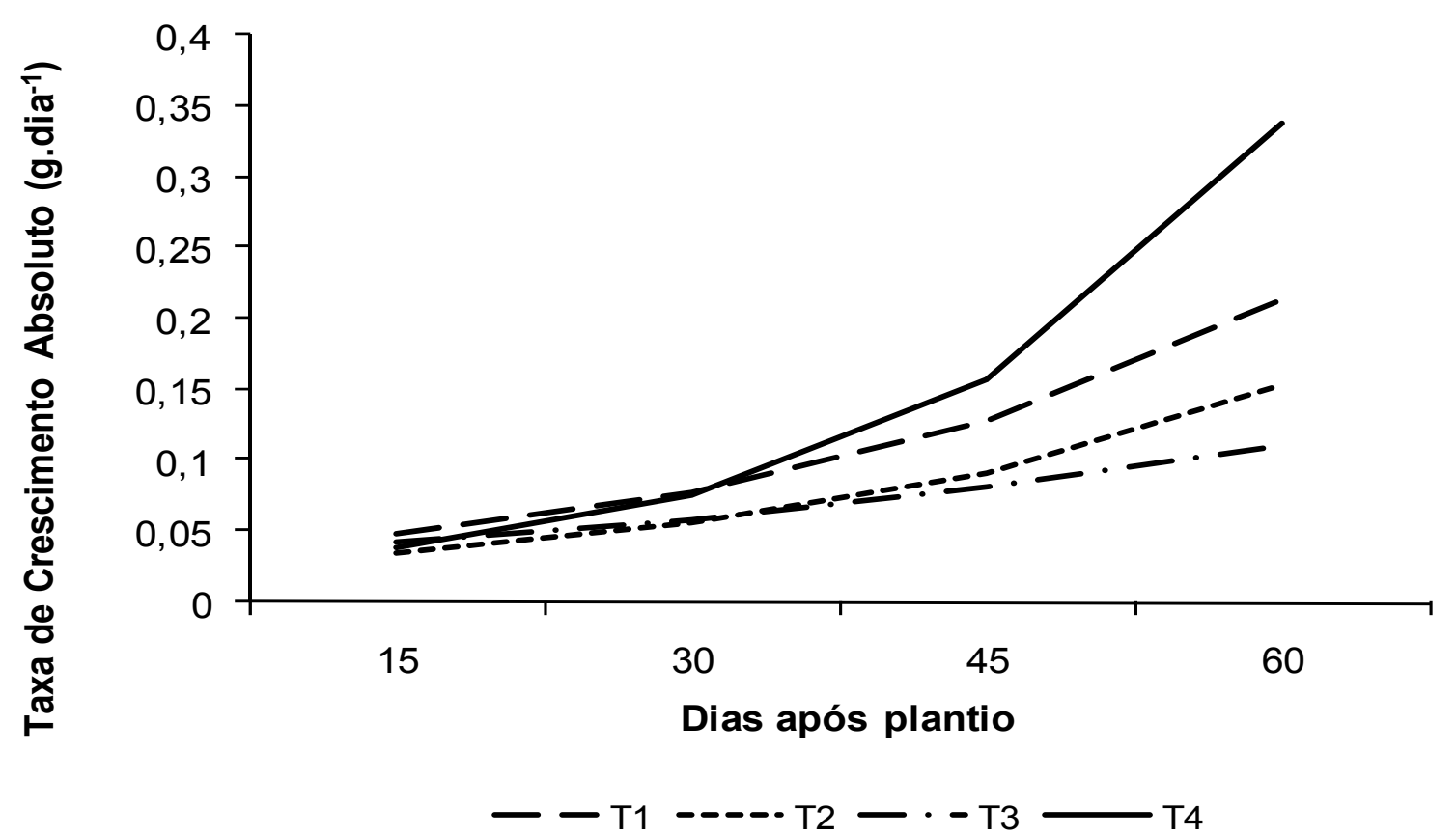

Figura 3. Taxa de crescimento absoluto de dois genótipos de Eucalyptus urograndis submetidos a diferentes potenciais de água no solo. Botucatu, 2009.

Os resultados obtidos para a taxa de crescimento relativo (TCR) dos dois genótipos estudados podem ser visualizados na Figura 4. O clone 433 apresenta crescimento significamente superior ao clone 105, quando estes não estão submetidos à estresse hídrico, o contrário se observa nos tratamentos com restrição de água, onde nota-se maior acúmulo de material para clone 105.

Observando-se o comportamento da curva de TCR em todos os tratamentos, verificase maior diferenciação do acúmulo de material aos 60 DAP no clone 433 e para os tratamentos com o clone 105 isto ocorre no início do desenvolvimento das plantas, seguido por diminuição ao longo das coletas

Há uma tendência dos valores se igualarem mesmo com diferentes regimes hídricos, já que este parâmetro pode ser usado na observação da velocidade média de crescimento ao longo do período determinado.

Tais fatos podem ser explicados pelas diferentes respostas dos materiais genéticos aos manejos hídricos, já que este índice físiológico depende simultaneamente da eficiência assimilatória de suas folhas e da massa de área foliar (número de folhas/planta, tamanho da folha e peso destas) que varia conforme a disponibilidade de água no solo (Oliveira e Gomide, 1986) 
Em estudo realizado por Peixoto et al. (2007) com diferentes genótipos de citros cultivados sob déficit hídrico, verifica-se que todos os genótipos se relacionaram a valores positivos no período irrigado, declinando no período de déficit hídrico e apresentando taxas negativas, à exceção do híbrido HTR - 051. Este período de re-irrigação manifestou taxas positivas, indicando sua boa capacidade de recuperação quando re-irrigados, comprovando as diferentes respostas de materiais genéticos submetidos a manejos hídricos distintos.

Sendo a TCR uma estimativa da eficiência da planta em acumular matéria seca, podese inferir que o clone 105 foi o genótipo que apresentou maiores possibilidades de tolerar o déficit hídrico, bem como de aumentar seu crescimento, já que a eficiência de produção por unidade de matéria seca durante o período de pegamento da muda de eucalipto foi maior que o do clone 433, o que indica seu potencial de uso em ambientes sujeitos a plantio durante estiagem prolongada.
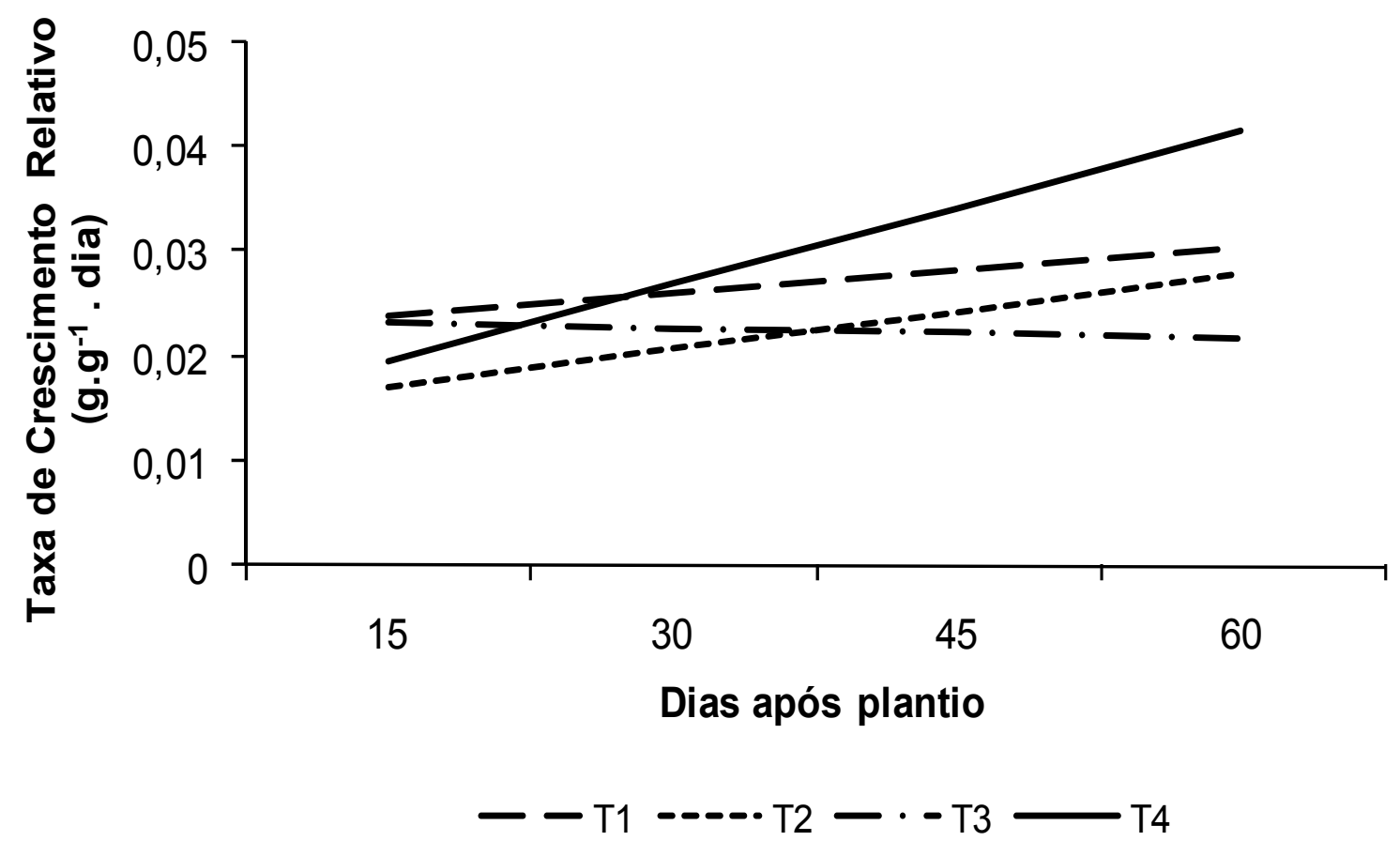

Figura 4. Taxa de crescimento relativo de dois genótipos de Eucalyptus urograndis submetidos a diferentes potenciais de água no solo. Botucatu, 2009.

Os valores médios da taxa assimilatória líquida (TAL), nos diferentes regimes hídricos, são apresentados na Figura 5 e refletem a dimensão do sistema fotossintético que é envolvido na produção de matéria seca.

Observa-se aos 30 DAP, os maiores valores em todos os tratamentos, isto, provavelmente, devido à turgescência foliar, permitindo a abertura estomática e favorecendo as trocas gasosas, com a entrada de $\mathrm{CO}_{2}$, de forma a atender à grande demanda de assimilados dos órgãos em crescimento. A partir dos 45 DAP, há uma queda nos índices de TAL, menos evidente no tratamento 4 (clone 433 sem restrição hídrica), sendo que este apresenta valores superiores aos demais, indicando a maior eficiência fotossintética do mesmo, permitindo as trocas gasosas e, conseqüentemente, favorecendo o aumento da fotossíntese. Os baixos valores de TAL para o clone 105 pode ter sido ocasionado pela produção de folhas maiores e 
ocasionado o auto-sombreamento, proporcionando menor assimilação de $\mathrm{CO} 2$ durante o ciclo da planta.

Segundo Milthorpe e Moorby (1974), a TAL comumente diminui com a idade das plantas devido ao sombreamento das folhas inferiores. Essa afirmativa é concorde com os registros de Valmorbida (2003) que atribuiu a diminuição da TAL em Mentha piperita L., cultivada com diferentes níveis de potássio, ao aumento da área foliar, responsável pelo maior sombreamento das folhas inferiores.
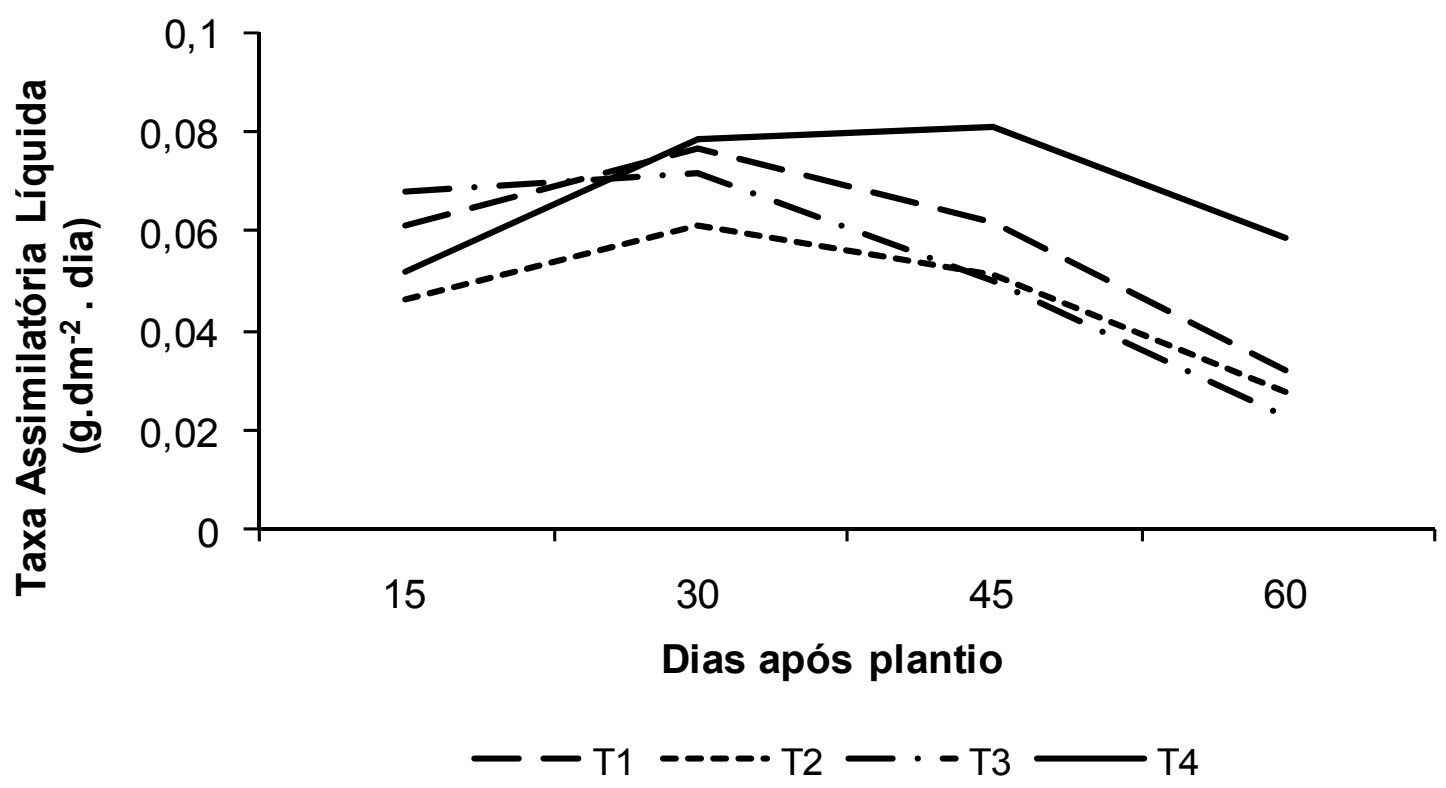

Figura 5. Taxa assimilatória líquida de dois genótipos de Eucalyptus urograndis submetidos a diferentes potenciais de água no solo. Botucatu, 2009.

Segundo Magalhães (1979) a Razão Área Foliar (RAF) é a medida da dimensão do aparelho assimilador, e serve como parâmetro apropriado para as avaliações de efeitos genotípicos, climáticos e do manejo de comunidades vegetais. Este parâmetro expressa a área foliar útil para a fotossíntese. Na Figura 6 observa-se um comportamento inverso da TAL, também verificado por Barreiro et al. (2006) em estudo com manjericão, em que o tratamento T4 obteve menores valores ao final do 60 DAP. Independentemente do tratamento a que as plantas foram submetidas, a RAF manteve-se constante ate os $45 \mathrm{DAP}$, havendo um rápido crescimento após esse período.

Diversos autores sugerem que a RAF alcança valores máximos no início do ciclo vegetativo e posteriormente decrescendo com a maturação da planta (Ferreira, 1996; Peixoto, 1998; Brandelero, 2001 e Povh, 2004). Segundo Benincasa (2003), a RAF expressa a área foliar útil para a fotossíntese, sendo relação entre a área foliar responsável pela interceptação da energia luminosa e $\mathrm{CO}_{2}$ e a massa seca total, resultado da fotossíntese. Desse modo, com o crescimento da planta, aumenta a interferência das folhas superiores sobre as inferiores, diminuindo a área foliar útil.

No presente estudo, devido ao pequeno período de avaliações, não foi observado este decréscimo na RAF, pois pressupõem-se que a taxa máxima não foi atingida, já que a espécie Eucalyptus sp., uma planta perene, tem crescimento lento em comparação a outras culturas. 


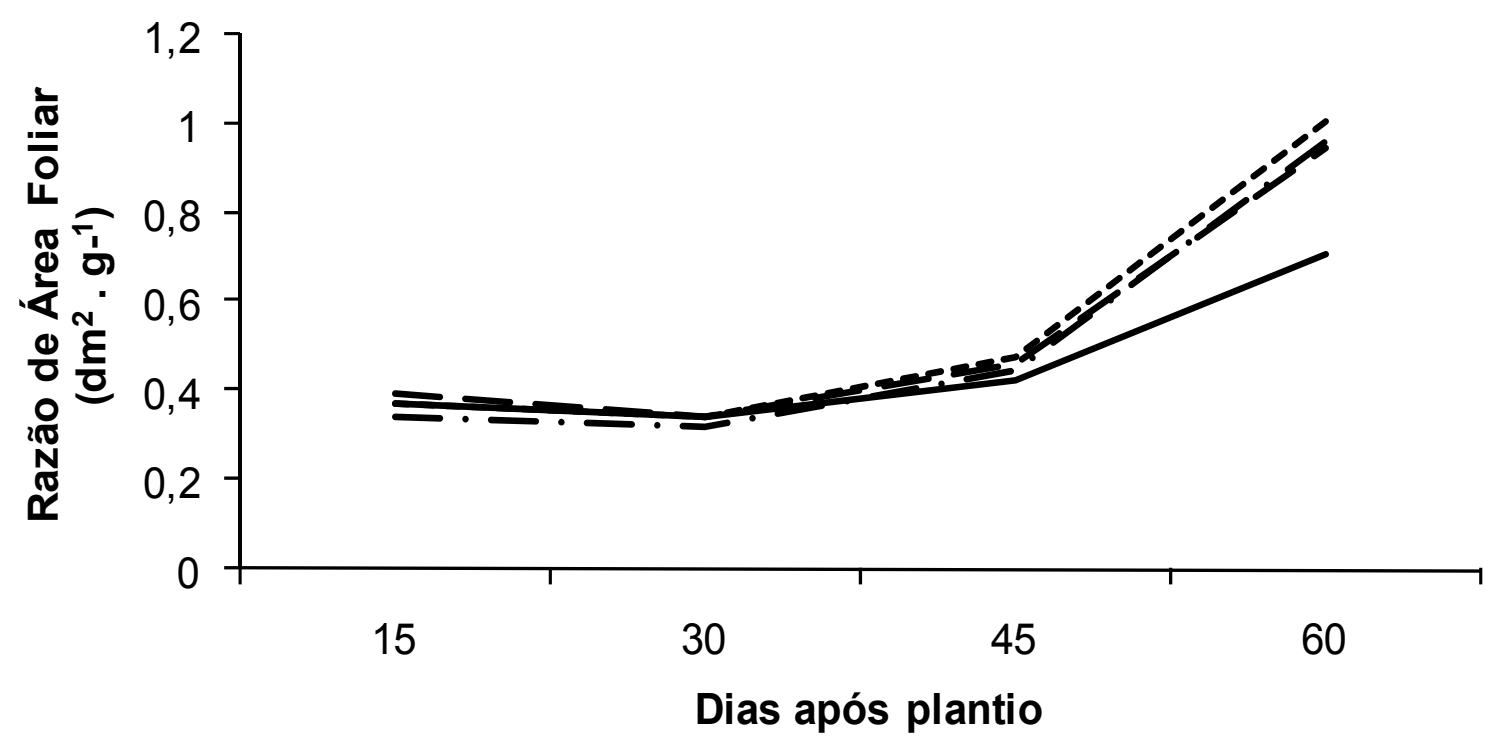

$--\mathrm{T} 1-\cdots \mathrm{T} 2-\cdot-\mathrm{T} 3-\mathrm{T} 4$

Figura 6. Razão de área foliar de dois genótipos de Eucalyptus urograndis submetidos a diferentes potenciais de água no solo. Botucatu, 2009.

A Área Foliar Específica (AFE) é expressa pela razão entre a área foliar e a massa seca das folhas. A área foliar é um componente morfofisiológico e a massa um componente anatômico de uma espécie vegetal, pois está relacionado à composição interna (número e tamanho) das células do mesofilo (Barreiro, 2006). Infere-se daí, que o inverso da AFE reflete a espessura das folhas (Benincasa, 2003). Ferreira (1996) relata que decréscimos na AFE indicam aumento na espessura da folha resultante do aumento e do tamanho do número de células nas plantas. De maneira geral, o comportamento da AFE (FIGURA 7) é semelhante ao da RAF, diminuiu ao longo do ciclo das plantas, fato não observado no presente trabalho, devido ao período de estudo. Nas plantas tratadas com restrição hídrica, ocorreram os maiores valores para essa variável, não sendo verificada diferenças entre os tratamentos ao qual o clone 105 foi submetido, e menores valores para o clone 433 sem restrição hídrica. Este fato pode ser explicado devido à maior espessura das folhas, produzindo maior massa seca, sendo este componente responsável pela variação da AFE. A partir dos 45 DAP nota-se aumento em todos os tratamentos, podendo-se inferir que, inicialmente, as folhas das plantas de eucalipto acumulam reservas para depois ocorrer translocação para outros órgãos.

Segundo Benincasa (2003), no início do desenvolvimento, os valores da AFE podem ser maiores, revelando folhas pouco espessas, com pouca massa seca e área foliar. Com o desenvolvimento das plantas, aumentam-se a área foliar e a massa seca de folhas, com a queda dos valores dessa variável. A partir dos resultados pode-se também inferir que, inicialmente, as folhas das plantas de $O$. basilicum L. acumulam reservas para depois ocorrer translocação para outros órgãos. 


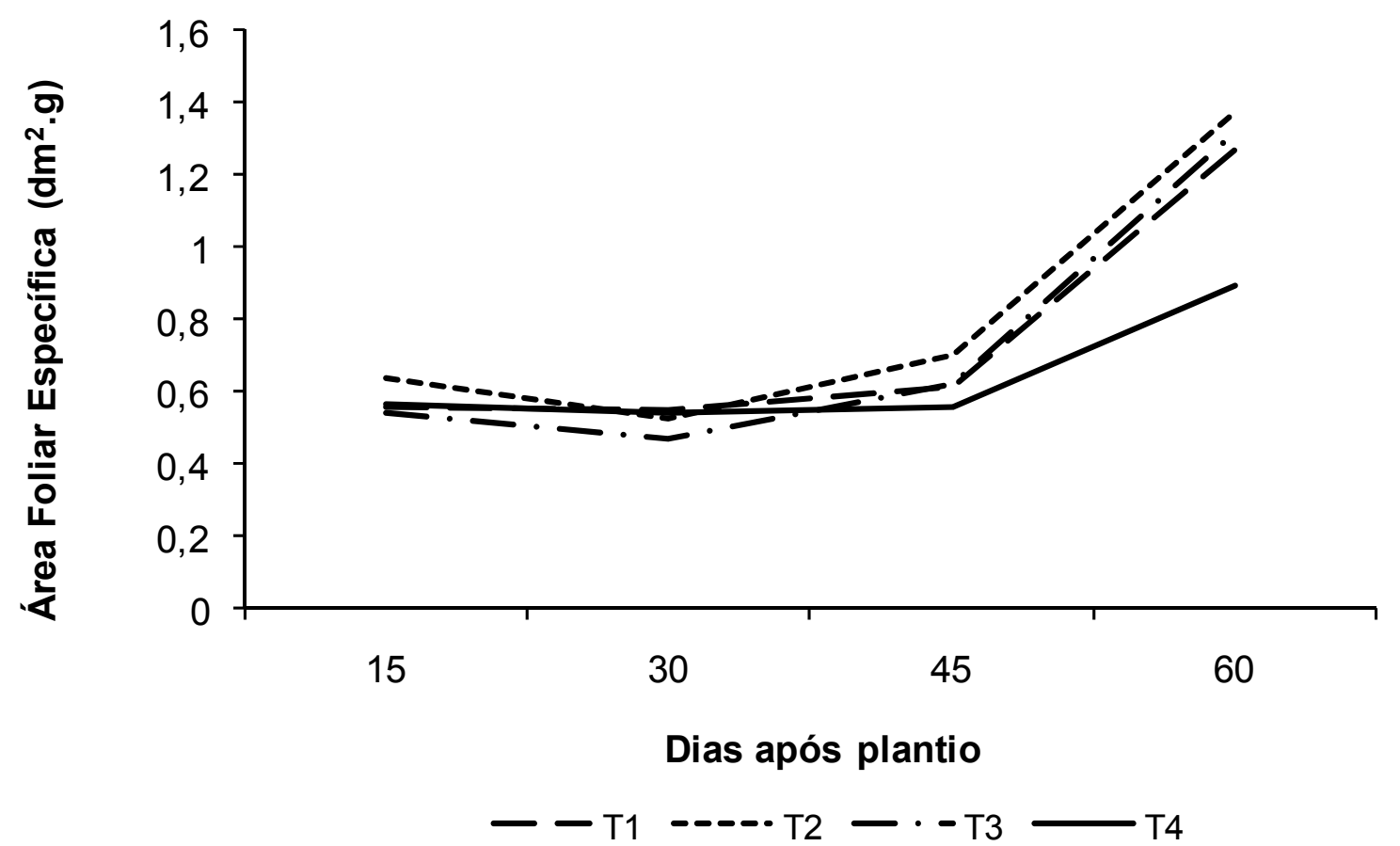

Figura 7. Área foliar específica de dois genótipos de Eucalyptus urograndis submetidos a diferentes potenciais de água no solo. Botucatu, 2009.

\section{CONCLUSÕES}

Os dois materiais genéticos tem alto poder de desenvolvimento sob condições hídricas favoráveis. O clone 433 mostrou-se mais sensível ao estresse hídrico, com menores valores de massa seca e IAF, pode-se assim inferir que o clone 105 possui maior eficiência no uso da água e de tolerar o déficit hídrico.

\section{REFERÊNCIAS BIBLIOGRÁFICAS}

BARREIRO, A. P.; ZUCARELI, V.; ONO, E. O; RODRIGUES, J. D. 2006. Análise de crescimento de plantas de manjericão tratadas Com reguladores vegetais. Bragantia, Campinas, v.65, n.4, p.563-567.

BENINCASA, M.M.P. 2003. Análise de crescimento de plantas: noções básicas. Jaboticabal: FUNEP, 41p.

BRAGA, M. B., KLAR, A. E. 2000. Evaporação e evapotranspiração de referência em campos e em estufas orientadas nos sentidos norte/sul e leste/oeste. Irriga, Botucatu, v.5, n.3.

BRANDELERO, E. M.; PEIXOTO. C. P.; SANTOS, J. M .B. S.; MORAES, J. C. C. M.; SILVA, V. 2002. Índices fisiológicos e rendimento de cultivares de soja no recôncavo bahiano. Magistra, Cruz das Almas, v. 14, n. 2, p. 77-88. 
CARDOSO, M. J.; FONTES, L. A. N. ; LOPES, N. F. ; et al. 1987. Partição de assimilados e produção de matéria seca de milho em dois sistemas de associação com feijão (Phaseolus vulgares L.). Revista Ceres, Viçosa, v. 34, n. 191, p. 71-89.

FERREIRA, E. 1996. Ajustamento osmótico e análise de crescimento de plantas de milho (Zea mays L.), em função do nível de potássio e estresse hídrico. Tese (Doutorado) Universidade Estadual Paulista, Botucatu.

GOMES, A. G; VARRIALE, M. C. 2001. Modelagem de Ecossistemas: Uma Introdução. Santa Maria - RS - Brasil: Editora da Universidade Federal de Santa Maria, v. 01. 504 p.

GUIMARÃES, R. J. 1994. Análise do crescimento e da quantificação de nutrientes em mudas de cafeeiro (Coffea arábica L.), durante seus estádios de desenvolvimento em substrato padrão. Dissertação - (Mestrado em Fitotecnia) - Faculdade de Ciências Agronômicas, Universidade Estadual Paulista, Botucatu.

HUNT, R. 1982. Plant growth curves the functional approach to plant growth analysis. Ed. Edward Arnold, Londres, 248 p.

IBARRA R., W.E. 1985. Comparación y validación de métodos de estimación de área foliar en ocho cultivares de sorgo granífero (Sorghum bicolor (L.) Moench). Maracay, 112p. Tesis de grado - Facultad de Agronomía, U.C.V,

JORGE Y; GONZÁLEZ F. 1997. Estimación de área foliar em los cultivos de ají y tomate. Agrotecnica de Cuba, 27: 123-130.

KLAR, A.E. 1984. Evapotranspiração. In: A água no sistema solo-planta-atmosfera. 2ed. São Paulo: Nobel, 408 p.

LANG, A. R. G.; McMURTRIE, R. E. 1992, Total leaf areas of single trees of Eucalyptus urograndis estimated from transmittances of the sun's beam. Agricultural and Forest Meteorology, v. 58, p. 79-92.

LARCHER, W. 2000. Plantas sob estresse. In: Ecofisiologia Vegetal. São Carlos: Editora RIMA, p.341-430.

MAGALHÃES, A.C.N. 1979. Análise quantitativa do crescimento. In: FERRI, M.G. Fisiologia Vegetal. EPU/EDUSP, São Paulo. v. 1, p. 331-350.

MILTHORPE, F.L.; MOORBY, J. 1974. Some aspects of overall growth and its modification. In: MILTHORPE, F.L.; MOORBY, J. Na introduction to crop physiology. London: Cambridge University Press, p.152.

NeSMITH, D. S.; RITCHIE, J. T. 1992. Short-and. Long Term Responses of corn to a PreAnthesis Soil Water Deficit. Agron. J. Madison, v.84, p. 107-113.

OLIVEIRA, L. E. M.; GOMIDE, M. B. 1986. Fisiologia Vegetal. Lavras, Esal, 72 p. 
PEIXOTO, C. P. 1998. Análise de crescimento e rendimento de três cultivares de soja em três épocas de semeadura e três densidades de plantas. Tese - (Doutorado em Fitotecnia) Escola Superior de Agricultura "Luiz de Queiroz", Universidade de São Paulo, Piracicaba.

PEIXOTO, C. P.; CERQUEIRA, E. C.; SOARES FILHO, W. S.; CASTRO NETO, M. T.; LEDO, C. A. S.; MATOS, F. S.; OLIVEIRA, J. G. 2007. Análise de crescimento de diferentes genótipos de citros cultivados sob déficit hídrico. Revista Brasileira de Fruticultura, Vol. 28, $\mathrm{N}^{\circ} 03$.

PEREIRA, A.R., MACHADO, E.C. 1987. Análise Quantitativa do Crescimento de Comunidades Vegetais. Instituto Agronômico de Campinas (IAC), Campinas, SP. Boletim Técnico. n. 114. 33 p.

PEREIRA, M. R. R.; KLAR, A. E.; SILVA, M. R.; SOUZA R. A.; FONSECA. N. R. 2006. Comportamento fisiológico e morfológico de clones de Eucalyptus urograndis submetidos a diferentes níveis de água no solo. Irriga, Botucatu, v. 11, n. 4, p. 518-531 outubro-dezembro.

POVH, J.A. 2004. Efeitos de reguladores vegetais no desenvolvimento de plantas de Salvia officinalis L. e na produção de óleo essencial. Dissertação (Mestrado) - Instituto de Biociências, Universidade Estadual Paulista. Botucatu.

SHARMA, B. D.; KAUL, H. N.; SINGH, M. 1993. Growth analysis of potato varieties in autumn in subtropical conditions. New Botanist, Lucknow, v. 20, n. 54, p. 55-64.

SOARES, J. V.; ALMEIDA A. C.; PENCHEL R. M. 1997. Balanço hídrico de plantações de eucalipto a partir da estimativa de transpiração pelo método de Penman-Monteith (Hydrological balance of eucalypt plantations through transpiration by the method of PenmanMonteith). In: International union of forest research organizations (iufro) conference on silviculture and improvement of eucalypts, Salvador. Anais... Salvador: v. 4, p. 52-61.

SOARES, J. V.; ALMEIDA, A. C. 2001. Modelling the water balance and soil water fluxes in a fast growing eucalypt plantation in Brazil. Journal of Hydrology, v. 253, p. 130- 147.

TONELlO, K. C.; TEIXEIRA FILHO, J. 2007. Respostas fisiológicas de dois clones de eucalipto submetidos a diferentes potenciais hídricos. I Seminário de Recursos Hídricos da Bacia Hidrográfica do Paraíba do Sul: o Eucalipto e o Ciclo Hidrológico. Anais... Taubaté, Brasil, IPABHi, p. 287-294.

VALMORBIDA, J. 2003. Níveis de potássio em solução nutritiva, desenvolvimento de plantas e produção de óleo essencial de Mentha piperita L. Dissertação (Mestrado) Faculdade de Ciências Agronômicas, Universidade Estadual Paulista, Botucatu.

WATSON, D. J. 1947. Comparative physiological studies on growth of field crops: I. Variation in net assimilation rate and leaf area between species and varieties, and within and between years. Annals of Botany, v. 11, p. 41-76. 